\author{
WHAT'S IN A NAME? \\ PERCEPTIONS OF COURSE NAMES FOR CRIMINAL JUSTICE \\ PROFESSIONALS \\ Richard Wortley \\ \& \\ Kerry Wimshurst
}

School of Criminology and Criminal Justice

Griffith University

Brisbane 4111

Cite as:

Wortley, R., and Wimshurst, K. (2000) What's in a name? Perceptions of course names for criminal justice professionals. Journal of Criminal Justice Education, 11, 267-278. 


\begin{abstract}
Courses dealing with crime and the criminal justice system go under various names, Criminology, Criminal Justice, Justice Studies, and Justice Administration being among the most popular. Presumably, those who name these courses see subtle differences between these names and select a title, which is seen to best reflect the particular focus of their course. For example, in Australia Justice Administration has been generally used for courses that have an explicit vocational mission. This paper, however, is not about what these various courses contain, but what people think they contain. The paper reports on a study that examined the perceptions of various course names by prospective and current students in the field. It is argued that the name of a course has significant implications for the attractiveness of that course to prospective students and the way that students in a course define their studies. Moreover, the meanings that students attach to course names seem to impact upon their sense of occupational identity.
\end{abstract}




\section{WHAT'S IN A NAME? PERCEPTIONS OF COURSE NAMES FOR CRIMINAL}

\section{JUSTICE PROFESSIONALS}

During the 1990s a number of undergraduate programs in criminal justice were established at Australian universities. The impetus for founding these new programs varied by region, but a major aim of all of them has been to enhance the ‘professionalism’ of criminal justice systems by offering degree level studies to current and intending personnel in the field. In the case of the state of Queensland, for example, courses were established at two universities in Brisbane -- Griffith University and the Queensland University of Technology (QUT) -- following the Fitzgerald Commission of Inquiry into police misconduct and corruption (19871989). Official inquiries and royal commissions in other states have also drawn attention to what they conclude is the necessity for tertiary level qualifications for police officers and those in related justice professions (Fitzgerald, 1989; Johnston, 1991; Lusher, 1981; Wood, 1997). There are now around 18 undergraduate courses in the area of criminal justice offered by some 15 universities across Australia.

While studies in criminology have been offered by some of the more established universities for decades, the newer programs in criminal justice originated in the more recently-established universities which grew out of the massive restructuring in Australian higher education in the late 1980s. These new programs certainly saw themselves as being vocationally oriented in that they wished to equip graduates with the appropriate knowledge and skills to gain employment in some area of criminal justice -- although, again, the emphasis placed upon vocationalism tended to vary across programs. Both of the Queensland programs saw themselves as striving to 
strike a balance in their respective offerings between, on the one hand an understanding of the criminal justice system, and on the other a solid grounding in criminological theorizing and research.

In some ways, the Australian situation now resembles the scene in the United States in the late 1960s and early 1970s when criminal justice programs were established at hundreds of universities and colleges in the US. Pre-service and in-service programs in these institutions were often designed to cater for two main client groups, the police and corrections officers. Then, however, when law enforcement funding for such programs started to be withdrawn in the 1970s, institutions found themselves confronting an uncertain future - indeed, many programs ceased to exist. Other programs adapted to changed circumstances by developing different emphases and approaches and by attracting and catering for a wider range of clients (see, for example, Durham, 1992). In Australia, the new degrees have continued to service personnel already working in criminal justice, but in addition have attracted an increasing proportion of younger students. In fact, the majority of students in most of these degrees are now relatively recent school-leavers.

While the current programs in Australia all appear to be quite buoyant, the present research grew out of a perception that stakeholders (university staff, students and employers) might have widely differing views about the nature of criminal justice education. Moreover, anecdotal evidence suggested that the actual naming of programs might generate considerable differences of opinion in people's minds about the aim and content of criminal justice courses. A question that started to emerge was whether the meanings that course developers attach to program names readily 
translate into signifying programs that other stakeholders feel will meet their own aspirations and expectations. Those who had developed the new degrees were concerned to avoid the apparent bifurcation between the interests of criminologists on the one hand, and 'criminal justicians' on the other, which according to commentators had tended to characterize earlier criminal justice education in the US (see, for example, Sorensen, Widmayer and Scarpitti, 1994; Finckenauer and Laufer, 1996). To return to the Queensland situation as an example, it is clear that the 'named degrees' at the two universities, one a Bachelor of Arts in Justice Administration (at Griffith), and the other in Justice Studies (at QUT), both sought in their titles to capture a sense of engagement with the 'real world' of doing justice. They aimed to develop graduates who comprehend the criminal justice system as a whole (rather than focusing their aspirations and interests upon component agencies), who could confidently enter criminal justice professions yet maintain a constructively critical perspective on their own practices.

Over time, however, it seemed that other stakeholders might have divergent understandings of the new programs and the research reported here grew out of two concerns. First, it was felt that identifying the meanings that students and others attach to alternative course names has practical implications because it can provide insight into what people think they are doing when they enter an undergraduate degree in criminal justice. The name of a degree and associated meanings also might well have considerable implications for the perceived employability of graduates. Second, the identity of a degree - what its name signifies -- might have implications for student identity as these (mainly) young people move toward developing their occupational identities and start to formulate career aspirations. For example, in 
Australia ‘justice administration' as well as being the name of a degree at one of the universities, is also a generic term commonly used to encompass the range of 'named degrees' in criminal justice. Yet students in particular have complained that the term makes little sense to the public or prospective employers. In fact, to many stakeholders, the term seems to imply activities associated vaguely with the duties of a legal secretary. Thus at a time when undergraduates are struggling through an important developmental stage in their lives - the formulation of career identity - the meanings that they attach to the names of their degree programs might have considerable impact upon facilitating or constraining their career aspirations. Marcia (1980) has noted the importance played by the development of 'vocational commitment' (that is, a broad understanding of what one might want to do with one's life in terms of work or 'industry') in the formation of a person's identity or sense of self. Moreover, the development of a sense of vocation might be doubly difficult for students in an era when the link between qualifications and where graduates enter the job market has become increasingly uncertain (Nowotny, 1995). In an attempt to understand the link between meaning-making and identity, this paper explores the perceptions that students currently undertaking a degree in justice administration have of alternative course names.

\section{METHOD}

\section{$\underline{\text { Participants }}$}

Two-hundred and fifty-six students of Griffith University (Brisbane) were asked to participate in the study. Twenty four of these students subsequently produced unusable data and were excluded from further analysis. Of the remaining 232 participants, 77 were male and 154 female (1 no response); 180 were enrolled in the 
Bachelor of Arts in Justice Administration degree while 50 were from other courses taking one or more Justice Administration subjects as electives (2 no response); 104 were new students who had not yet attended any University classes and 128 were current students; 67 identified policing as their target career and 159 identified some other career path (6 no response). The mean age of participants was 22.9 years.

\section{$\underline{\text { Materials }}$}

A questionnaire was constructed to examine perceptions of 5 alternative names -Justice Administration (JA), Justice Studies (JS), Criminal Justice (CJ), Criminology (C), and Criminology and Criminal Justice (CCJ). The questionnaire was in two parts. The first part required respondents to rate these alternatives as course names using a ten-item semantic differential. The semantic differential involved polar descriptions placed at either end of a nine-point scale, and subjects were required to mark the position along the scale that represented their opinion. Five scales were in the positive direction and five in the negative direction in order to minimize response sets. In addition, the order of the scales was randomly varied for each name. The ten attributes were 'very theoretical/not at all theoretical', 'very dull/very interesting', 'very easy/very difficult', 'highly regarded/not highly regarded', 'not at all useful/very useful', 'very in-depth/very superficial', 'not at all academic/very academic’, 'very challenging/not at all challenging', 'very specialized/very general', and 'very vocational/not at all vocational'.

The second part of the questionnaire required respondents to rate the five alternatives as school or department names. It was reasoned that students' identity might derive not just from the name of their award, but also the name of the university school they 
attended. Again a ten-item semantic differential was employed. In this case the attributes were 'not at all friendly/very friendly', 'very radical/very conservative', 'very prestigious/not at all prestigious', 'in touch with the real world/not in touch with the real world', 'not research oriented/research oriented', 'highly qualified/poorly qualified', 'not at all active/very active', ‘very narrow/very diverse’, 'very socially aware/not socially aware', and 'teaching oriented/not teaching oriented'.

\section{Procedure}

Current students were asked to complete questionnaires at the end of lectures and tutorials. New students were asked to complete questionnaires during orientation week information sessions. It was stressed to participants that the questionnaires sought their perceptions of the names in general, not their evaluations of any particular courses or schools using these names.

\section{RESULTS}

\section{Differences Between Names}

The first set of analyses examined overall differences in the evaluations of the five names. Table 1 shows the mean ratings for each name on the twenty scales. These data were examined in two repeated measures MANOVAs, one with the 10 courseratings as the dependent set, and the other with the 10 school/department-ratings as the dependent set. In both cases, the five names formed the within-subjects factor. These analyses revealed significant differences in the ratings of both the course and school names $(\mathrm{F}(40,192)=12.01, \mathrm{p}<.0001$, and $\mathrm{F}(40,192)=14.35, \mathrm{p}<.0001$ respectively). 


\section{TABLE 1 ABOUT HERE}

Follow-up analyses examined all 10 pair-wise comparisons among the names for both sets of data to examine the exact pattern of the differences. Given the large number of analyses, Bonferroni adjustment was applied and alpha set at .005 in order to protect against type-one error. These results are summarized in Table 2. It can be seen that all multivariate tests were significant indicating that each name was rated to be significantly different overall from every other name. An examination of the univariate tests in conjunction with the means shown in Table 1 indicates that, generally speaking, the order of the evaluations from least positive to most positive is Justice Studies, Justice Administration, Criminal Justice, Criminology, and Criminology and Criminal Justice. Not surprisingly, there were somewhat fewer univariate differences between adjacent pairs in this ordering (i.e., JS and JA, JA and CJ, CJ and C, and C and CCJ) than for non-adjacent pairs. When the bottom-rating names (JS and JA) are compared with the top rating names (C and CCJ) differences appear on almost all attributes. Perhaps most surprisingly, the terms Justice Studies and Justice Administration - the names of the degree offered by the two universities in Queensland --are not even successful in fulfilling their original purpose of defining the field for criminal justice professionals. For example, Criminology is rated to be more useful and in touch with the real world than either Justice Studies or Justice Administration.

A particularly interesting result was the cumulative effect of combining Criminology and Criminal Justice. The composite term retains the perceived academic strengths of Criminology while capitalizing on the more applied flavor of Criminal Justice. Thus, 
Criminology and Criminal Justice conveys a more vocational and less radical image than Criminology, but at the same time is still viewed to be as theoretical, in-depth, challenging and so forth. Consistent with this dual applied/theoretical focus, the composite term also conveys a greater sense of breadth than either of the contributing terms singularly, with a school or department going by this name rated to be more qualified, diverse and socially aware.

\section{TABLE 2 ABOUT HERE}

\section{$\underline{\text { Differences Between Groups }}$}

Further analyses examined differences in the ratings of the names in terms of the various groups of students identified in the sample. Ten MANOVA were performed on the data, one for each of the ten sets of semantic differentials. In each case, the between-subjects factors were gender, student status (new student/current student), school status (Justice Administration student/other) and career path (police/other). Given the number of independent variables and the potential for uninterpretable interactions, only main effects were examined. Each factor was adjusted for all other factors.

\section{$\underline{\text { Student status }}$}

The main difference between new and current students was their respective evaluations of Justice Studies as both a course name $(\mathrm{F}(10,209)=3.10, \mathrm{p}<.01)$ and school name $(\mathrm{F}(10,209)=2.88, \mathrm{p}<.01)$. New students regarded a Justice Studies course as more interesting, difficult, highly regarded, useful, in-depth, academic and challenging than did other students. Similarly, they regarded a Justice Studies school 
as more friendly, radical, prestigious, in touch with the real world, research oriented, highly qualified, active, diverse and socially aware than did other students. One explanation for theses findings is offered by social identity theory (Turner, 1984). As previously noted, there are two schools in Brisbane which offer courses in this field -the School of Justice Administration (at Griffith University, where the study was carried out) and the School of Justice Studies (at QUT). Social identity theory suggests that current students in the Justice Administration course will elevate their evaluations of the group to which they belong, and will correspondingly denigrate the opposing group (Justice Studies) in order to enhance their own self esteem. New students are yet to take on the group identity and so are relatively more approving of the outside group. Current students are much more aware than new students that graduates from both degree programs will be in competition for jobs in the field.

New students also tended to regard Criminology as a course name $(F(10,209)=1.92$, $\mathrm{p}<.05)$, Justice Administration as a course name $(\mathrm{F}(10,209)=1.98, \mathrm{p}<.05)$ and Criminology and Criminal Justice as a course name $(\mathrm{F}(10,209)=2.97, \mathrm{p}<.01)$ more positively than did existing student. However, these differences were less dramatic than was the case for Justice Studies, and principally involved the perception by new students that all of these courses were more interesting. This might be explained by the tendency for students to lose enthusiasm as they proceed in their studies (Gower and Kember, 1990).

\section{$\underline{\text { Gender }}$}

The main gender difference was the tendency for females to rate Criminal Justice as a course name more positively than did males $(F(10,209)=3.24, p<.01)$, seeing this 
name as more theoretical, interesting, useful, academic and specialized. The reason for these differences are unclear but may reflect a generally more positive view of university courses in the area by women.

\section{$\underline{\text { School Allegiance }}$}

The only difference between students enrolled in the Justice Administration course and other students (those from other courses taking occasional subjects in Justice Administration) was for the evaluation of Criminology and Criminal Justice as a school name $(F(10,209)=2.79, \mathrm{p}<.01)$. This involved only one attribute, with students within the school seeing this name as more prestigious than did other students.

\section{Career Path}

There was also only one difference between students planning to join the police and other students, in this case for the evaluation of Criminology as a course name $(\mathrm{F}(10,209)=1.99, \mathrm{p}<.05)$. Police-orientated students viewed this qualification as less useful than did non-police students. This finding confirms the experience of the authors, supported by the literature (Ellis, 1991; Shernock, 1992), that police-oriented students tend to be somewhat more instrumental in their studies and tend to regard ‘criminology’ as rather abstract.

\section{CONCLUSIONS}

This study has shown that students have a definite preference for the naming of courses in criminal justice. Of the five alternatives offered to them, Criminology and Criminal Justice carries a range of positive meanings. It is seen to encompass the 
depth and rigor normally associated with studies in criminology, while also conveying a sense of professional and vocational appropriateness.

It is noted that the current participants were associated with a particular program and that this association may have influenced their perceptions of the alternative names presented. While participants were asked to respond to the names in general terms opinions about specific programs may have biased their responses. Indeed there is some evidence that this did occur, in that current students were more denigrating of a rival program which is offered in the same city than were new students. At the same time, it might be considered remarkable that students within an existing course should hold such little allegiance overall to the name of their own program. They might have found the name of the course in a competing university to be less attractive than their own, but in absolute terms Justice Administration also rated poorly. In terms of developing an occupational identity, Justice Administration appears to be problematic as a descriptive label. As students in the course have sometimes commented, one can describe oneself as a 'criminologist', but what is a 'justice administrator'? The positive rating of the term criminology (whether singularly or in conjunction with criminal justice) would seem to reflect their desire to be able to identify with a recognized disciplinary area. Nevertheless, their preference for the combined term Criminology and Criminal Justice signals clearly that they want to be recognized as participating in the real-word of 'doing justice'. 


\section{REFERENCES}

Durham, A M (1992) Observations on the future of criminal justice education:

Legitimating the discipline and serving the general university population. Journal of Criminal Justice Education, Vol 3, No 1, 35-51

Ellis, R. (1991). Perceptions, attitudes and beliefs of police recruits. Canadian Police College Journal, 15(2), 95-117.

Finckenauer, J O and Laufer, W S (1996) The second generation of American criminal justice. Journal of Research in Crime and Delinquency, Vol 33, No 1, 5-15

Fitzgerald G E (Chairperson) (1989) Commission of Inquiry into Possible Illegal Activities and Associated Police Misconduct. Government Printer, Queensland

Gow, G and Kember D (1990) Does higher education promote independent learning? Higher Education, vol 19, No 3, 307-322

Johnston, E. (1991). National Report of the Royal Commission into Aboriginal Deaths in Custody. Canberra: Australian government Publishing Service.

Lusher, E. (1981). Report of Commission to Inquire into New South Wales Police Administration, Sydney: NSW Government Printer. 
Marcia, J E (1980) Identity in Adolescence. In J Adelson (ed) Handbook of Adolescent Psychology. Wiley: New York, pp159-187.

Nowotny, H. (1995) Mass higher education and social mobility: a tenuous link. In D. Dill and S. Sporn (eds) Emerging Patterns of Social Demand and University Reform: Through a Glass Darkly. IAU Press: Oxford, pp73-89.

Shernock, S. (1992). The effects of college education on professional attitudes among police. Journal of Criminal Justice Education, 3(1), 71-92.

Sorensen, J R, Widmayer, A G and Scarpitti, F R (1994) Examining the criminal justice and criminological paradigms: an analysis of ACJS and ASC members. Journal of Criminal Justice Education, Vol 5 No 2, 149-166

Turner, J.C. (1984) Social identification and psychological group formation. In H. Tajfel (ed) The Social Dimension: European Developments in Social Psychology (Vol 2) Cambridge: Cambridge University Press, pp 518-538.

Wood, J R T (Chairperson) (1997) Royal Commission into the New South Wales Police Service, Volume 2: Reform. New South Wales Government Printer. 
Table 1 Means for ratings of course and school attributes by students $(\mathrm{N}=232)$ (the lower the score the closer to the first-listed of the polar descriptors)

\begin{tabular}{lccccc}
\hline & JS & JA & CJ & C & CCJ \\
\hline Course & & & & & \\
Very theoretical/Not at all theoretical & 4.27 & 4.13 & 3.82 & 3.32 & 2.98 \\
Very dull/Very interesting & 4.93 & 5.61 & 6.20 & 6.75 & 6.77 \\
Very easy/Very difficult & 4.87 & 5.13 & 5.93 & 6.47 & 6.63 \\
Highly regarded/Not highly regarded & 5.08 & 4.52 & 4.07 & 3.25 & 2.91 \\
Not at all useful/Very useful & 5.65 & 6.06 & 6.36 & 6.56 & 6.81 \\
Very in-depth/Very superficial & 4.88 & 4.66 & 3.84 & 2.60 & 2.83 \\
Not at all academic/Very academic & 5.69 & 5.87 & 6.26 & 6.95 & 7.13 \\
Very challenging/Not at all challenging & 4.80 & 4.58 & 3.78 & 2.83 & 3.10 \\
Very specialized/Very general & 5.34 & 4.92 & 3.91 & 2.97 & 2.90 \\
Very vocational/Not at all vocational & 4.97 & 4.53 & 4.06 & 4.42 & 3.62 \\
& & & & & \\
School & & & & & \\
Not at all friendly/Very friendly & & & & & \\
Very radical/Very conservative & 5.45 & 5.47 & 5.63 & 5.46 & 5.30 \\
Very prestigious/Not at all prestigious & 5.79 & 6.29 & 5.43 & 4.92 & 5.34 \\
In touch with real world/Out of touch with real world & 4.77 & 4.20 & 3.92 & 3.65 & 3.75 \\
Not research oriented/Research oriented & 5.39 & 5.75 & 5.94 & 7.03 & 6.86 \\
Highly qualified/Poorly qualified & 4.98 & 4.35 & 3.84 & 3.21 & 2.44 \\
Not at all active/Very active & 5.03 & 5.52 & 5.52 & 6.16 & 6.41 \\
Very narrow/Very diverse & 5.17 & 5.60 & 4.76 & 4.91 & 5.83 \\
Very socially aware/Not socially aware & 4.35 & 4.13 & 4.19 & 3.62 & 3.13 \\
Teaching oriented/Not teaching oriented & 4.05 & 4.20 & 3.71 & 3.81 \\
\hline & & & & & \\
\hline
\end{tabular}


Table 2 Significant F values for all pair-wise comparisons of ratings among names

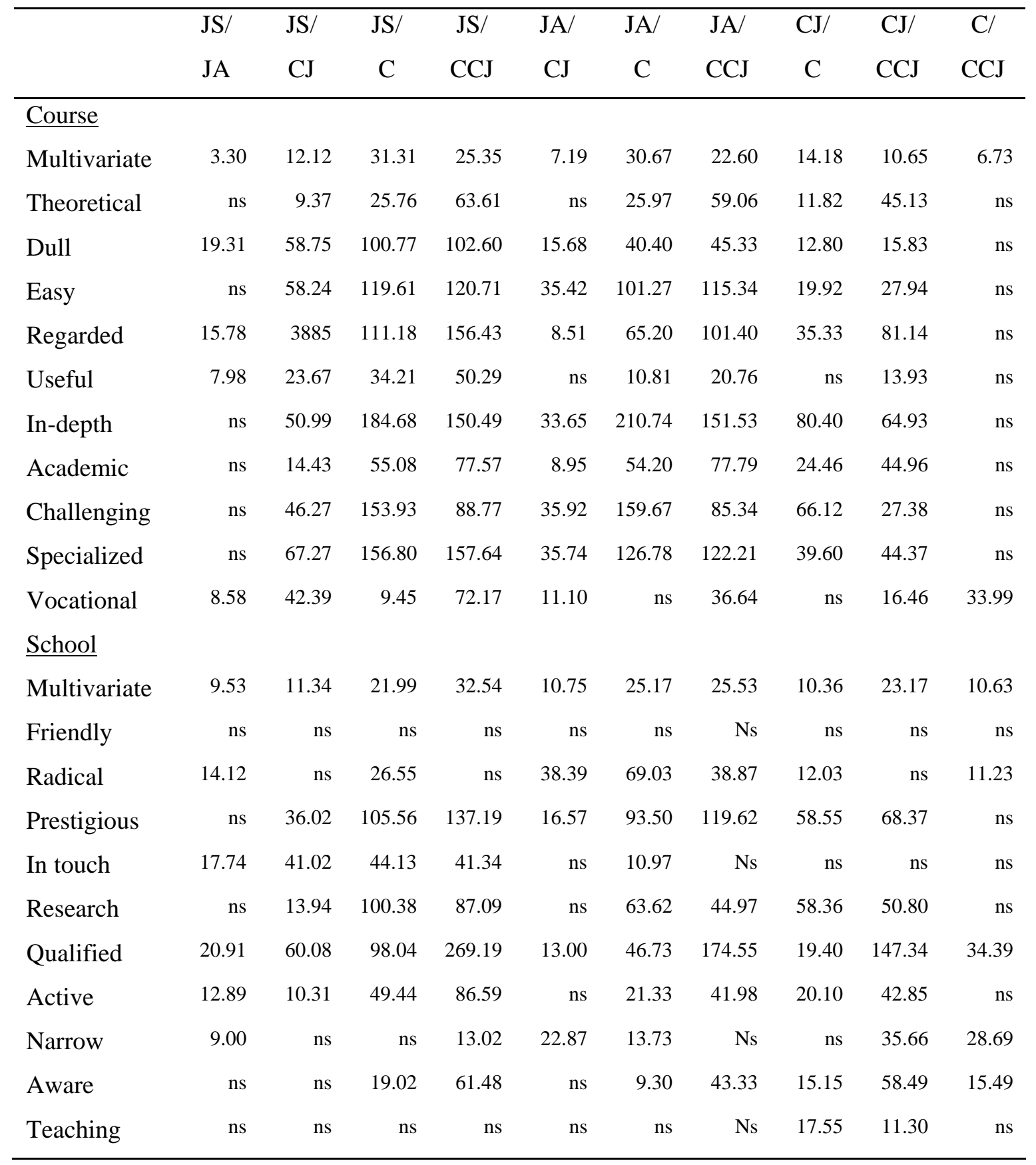

multivariate $\mathrm{df}=(10,222)$; univariate $\mathrm{df}=(1,231) ; \mathrm{p}<.005$ 